\title{
Analyzing the Process Capability for an auto Manual Transmission Base Plate MANUFACTURING
}

\author{
Manish Yadav ${ }^{1}$ and Manoj Kumar Sain ${ }^{2}$ \\ ${ }^{1}$ M.Tech. Student, Swami Keshvanand Institute of Technology, Management and \\ Gramothan, Jaipur \\ ${ }^{2}$ Reader, Swami Keshvanand Institute of Technology, Management and Gramothan, \\ Jaipur
}

\begin{abstract}
The industry today is working intensively on a goal-oriented way towards introducing regular studies in manufacturing. The current study is part of a large overall spanning project aiming towards an increase in productivity, i.e. more products produced per year with availability. In this paper we have analyze what Process Capability is and how it is implemented on a current process. All the steps are listed out in an easy to understand manner. In current scenario, specifications for products have been tightened due to performance competition in market. Statistical tools like control charts, process capability analysis and cause and effect diagram ensure that processes are fit for company specifications while reduce the process variation and improve product quality characteristic. Process capability indices (PCIs) are used in the manufacturing process to provide numerical measures on whether a process is capable of producing items within the predetermined limits. For the analysis purpose MINITAB 16.0 is used and is found that the process is placed exactly at the centre of the control limits. Analysis also shows that process is not adequate. The cause and effect diagram is prepared to found out the root cause of variation in diameter of work. In this study, a process-capability analysis was also carried out in a medium-sized company that produces machine and spare parts.
\end{abstract}

\section{KEYWORDS}

Process Capability, Process Capability Indices (PCIs)

\section{INTODUCTION}

Process Capability Study (PCS) is a scientific and a systematic procedure that analyzes and uses control charts to detect and remove the unusual causes of variation until a state of statistical control is reached. PCS is performed for a new or changed production process so as to verify the process capability or performance and achieve additional inputs for controlling the process [1]. Suitable methods need to be applied for monitoring and measurement of processes. These methods determine the ability of the processes to get desired results. When planned results are not achieved, corrective measures need to be taken, to ensure conformity of the product. The current study is part of a large aim that is more products produced per year with the available manufacturing equipments and a minimum of investments [1]. There are several capability indices, including $\mathrm{Cp}, \mathrm{Cpu}, \mathrm{Cpl}$ and $\mathrm{Cpk}$, that have been widely used in manufacturing process to provide common quantitative measures of process potential and performance. Process capability indices are powerful tools of studying the process ability for manufacturing a product that meets

DOI: $10.5121 /$ ijmvsc. 2016.7306 
specifications [3].We are using Base plate used in auto manual transmission for our study which is manufactured for a leading automobile company. In this research we take a close look at the procedure involved before a process capability is achieved

Table 1: Data Index and Estimate equation. [4]

\begin{tabular}{|l|l|l|}
\hline Index Symbol & Meaning & Estimated Equation \\
\hline $\mathrm{Cp}$ & Capability index & $($ USL-LSL)/6s \\
\hline $\mathrm{Cpu}$ & Upper Capability Index & $(\mathrm{USL}-\mathrm{X}$ Bar $) / 3 \mathrm{~s}$ \\
\hline $\mathrm{Cpl}$ & Lower Capability Index & $(\mathrm{X}$ Bar-LSL)/3S \\
\hline $\mathrm{Cpk}$ & Centering Capability Index & Min of (Cpu, Cpl) \\
\hline
\end{tabular}

\section{OBJECTIVE}

The aim of this project is to observe weather the operation done on the product are well in limits and if not how to overcome those variation. Following are the points on which we will focus during this study:

a) To prevent the product from deviation from a specification.

b) The continuous measure of improvement.

c) The identification of directions for improvement.

d) The auditing of the quality system.

\section{METHODOLOGY}

Process capability studies are recognized as able aids in improving a process. By PCS it is possible to establish best quality standards for the current process \& further improvement will so possible. Certain precautions are necessary before conducting PCS [2]:

a) Process should be in statistical control.

b) Independent data should be collected.

c) To make control Charts.

Process capability analysis steps are following [4]:

a) To collect samples at regular intervals or after production

b) To compute an appropriate statistics of product under consideration such as its range, sample mean etc.

c) To plot the statistics of the particular product on a chart as a function of sample number of time to reflect the quality of the remaining products.

d) To calculate the control line, upper control limit and lower control limit.

e) To observe the change and conclude

A control chart is made up of three lines.

- Central line (CL) which indicates the standard of process.

- Upper Control Limit (UCL).

- Lower Control Limit (LCL). 


\section{Control limit for $\mathbf{X}$ bar chart [7]}

$$
\begin{aligned}
& U S L=\bar{X}+A_{2} \bar{R} \\
& \text { Centre line }=\overline{\bar{X}} \\
& L S L=\bar{X}-A_{2} \bar{R}
\end{aligned}
$$

\section{Control limit for $\mathbf{R}$ chart [7]}

$$
\begin{gathered}
U S L=D_{4} \bar{R} \\
\text { Centre line }=\overline{\bar{X}} \\
\text { LSL }=D_{3} \bar{R}
\end{gathered}
$$

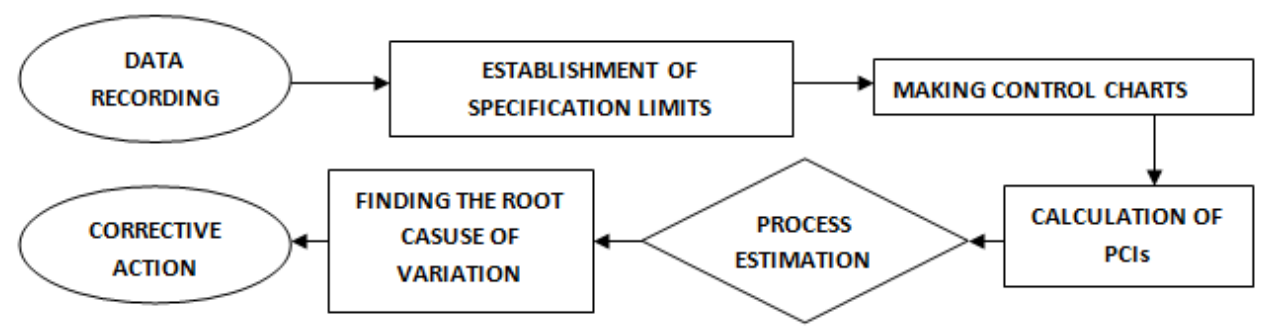

Fig 1: Steps of work

\section{PROCESS CAPABILITY RULES OF THUMB}

a) If $\mathrm{Cp}>1$ process is capable (product will fit between the customer's upper and lower specification limit if the process is centered).

b) If Cpk $>1$ process is capable and centered between the LSL and USL.

c) If $\mathrm{Cp}=\mathrm{Cpk}$ the process is at the middle point of the given specification limits.

d) If $\mathrm{Cp}>\mathrm{Cpk}$ the process is off-center.

e) If $\mathrm{Cpk}=1$ the process is barely capable.

f) If Cpk $<1$ the process is not capable.

g) $\mathrm{Pp}$ is the performance index. Like $\mathrm{Cp}$ it measures how well data fits within the USL and LSL. It make use standard deviation in the calculation instead of sigma estimator.

h) Ppk is the performance centering index. Like Cpk it measures how well your data is centered between the USL and LSL. It uses standard deviation for calculation instead of sigma estimator.

i) $\mathrm{Cp}$ and $\mathrm{Cpk}$ should be close in value to $\mathrm{Pp}$ and $\mathrm{Ppk}$.

j) If $\mathrm{Cp}$ and $\mathrm{Cpk}$ are much greater than $\mathrm{Pp}$ or Ppk, the process may not be stable. 


\section{PROCESS CAPABILITY ANALYSIS}

In this paper we have discussed an Auto Mobile product named Auto Manual Transmission Base Plate manufactured in Bhiwadi, India. This company is making a vast range of products that meets international standards. The focus of the study was to determine the process capability of a current process so as to decide upon the suitability of the machine to hold particular tolerance. A single sampling plan was enforced by using the lot-acceptance sampling plan. Samples were taken randomly during an ongoing boring process. The data for the analyzing characteristic was collected for 5 days in the company, determined for 25 samples (Observation Table).The machine used is Fanuc VMC.

The control chart for sample mean and ranges with their control limits are shown in Figure 2, 3, and 4. Control charts show that all points are within the control limits, so the process seems to be under control and stable. The control limits are as follows:

Table 2: Observation Table.

\begin{tabular}{|c|c|c|c|c|c|c|}
\hline \multirow{2}{*}{ Groups } & \multicolumn{5}{|c|}{ Diameter } & \multirow{2}{*}{$x$} \\
\hline & 1 & 2 & 3 & 4 & 5 & \\
\hline 1 & 9.01 & 9.01 & 9.02 & 9.03 & 9.01 & 9.016 \\
\hline 2 & 9.04 & 9.03 & 9.04 & 9.02 & 9.05 & 9.038 \\
\hline 3 & 9.05 & 9.01 & 9.04 & 9.06 & 9.03 & 9.038 \\
\hline 4 & 9.01 & 9.02 & 9.04 & 9.05 & 9.03 & 9.032 \\
\hline 5 & 9.02 & 9.03 & 9.01 & 9.04 & 9.05 & 9.03 \\
\hline 6 & 9.01 & 9.04 & 9.05 & 9.01 & 9.02 & 9.038 \\
\hline 7 & 9.04 & 9.02 & 9.02 & 9.03 & 9.01 & 9.024 \\
\hline 8 & 9.02 & 9.03 & 9.01 & 9.01 & 9.02 & 9.018 \\
\hline 9 & 9.04 & 9.05 & 9.05 & 9.01 & 9.04 & 9.04 \\
\hline 10 & 9.04 & 9.02 & 9.02 & 9.05 & 9.01 & 9.028 \\
\hline 11 & 9.01 & 9.02 & 9.01 & 9.02 & 9.05 & 9.024 \\
\hline 12 & 9.04 & 9.02 & 9.02 & 9.04 & 9.05 & 9.034 \\
\hline 13 & 9.01 & 9.04 & 9.01 & 9.04 & 9.02 & 9.024 \\
\hline 14 & 9.05 & 9.04 & 9.04 & 9.04 & 9.01 & 9.038 \\
\hline 15 & 9.03 & 9.04 & 9.04 & 9.05 & 9.03 & 9.04 \\
\hline 16 & 9.05 & 9.01 & 9.04 & 9.05 & 9.03 & 9.038 \\
\hline 17 & 9.01 & 9.02 & 9.04 & 9.05 & 9.03 & 9.032 \\
\hline 18 & 9.02 & 9.03 & 9.01 & 9.04 & 9.05 & 9.03 \\
\hline 19 & 9.01 & 9.04 & 9.05 & 9.01 & 9.02 & 9.038 \\
\hline 20 & 9.04 & 9.02 & 9.02 & 9.03 & 9.01 & 9.024 \\
\hline 21 & 9.02 & 9.03 & 9.01 & 9.01 & 9.02 & 9.018 \\
\hline 22 & 9.04 & 9.05 & 9.05 & 9.01 & 9.04 & 9.04 \\
\hline 23 & 9.05 & 9.01 & 9.04 & 9.06 & 9.03 & 9.038 \\
\hline 24 & 9.01 & 9.04 & 9.06 & 9.01 & 9.02 & 9.038 \\
\hline 25 & 9.04 & 9.06 & 9.05 & 9.01 & 9.04 & 9.04 \\
\hline
\end{tabular}




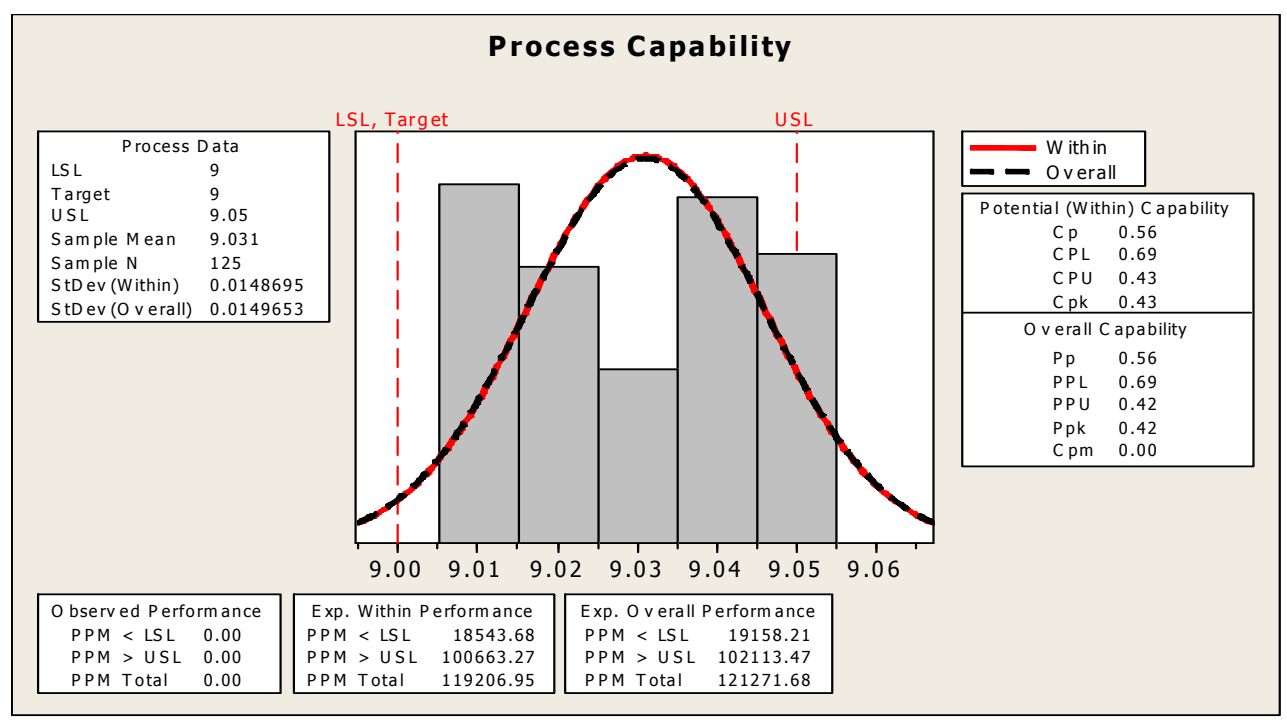

Fig 2: Process capability analysis

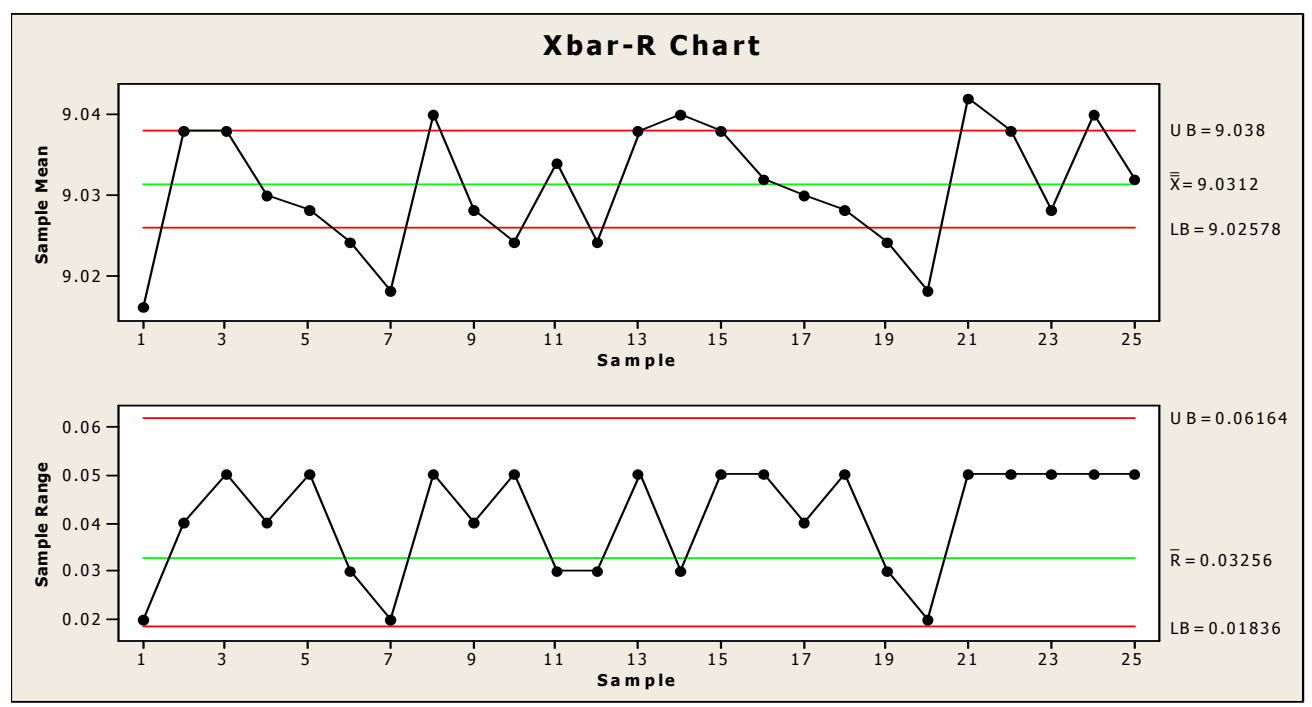

Fig 3: $\mathrm{X}$ and $\mathrm{R}$ Chart 


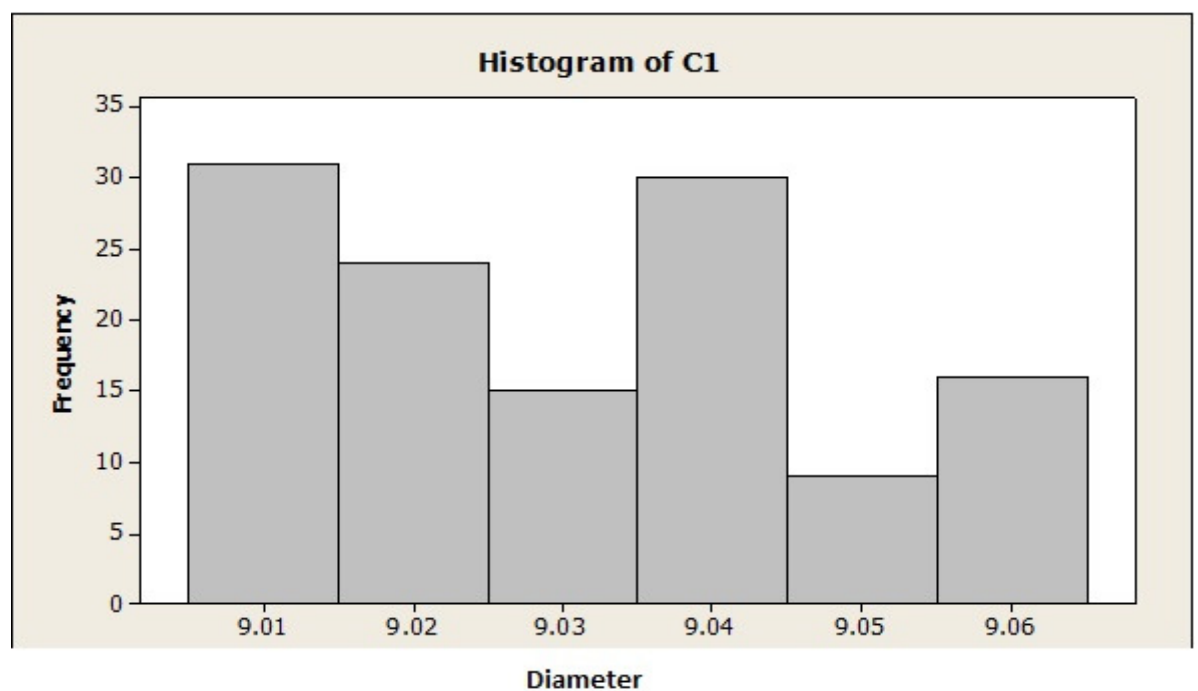

Figure 4: Histogram

\section{RESULTS AND DISCUSSION}

Table 3: Results

\begin{tabular}{|c|c|}
\hline $\mathbf{C}_{\mathbf{p}}$ & $\mathbf{0 . 5 6}$ \\
\hline $\mathbf{C}_{\mathbf{p k}}$ & $\mathbf{0 . 4 3}$ \\
\hline $\mathbf{U C L _ { \mathbf { X } }}$ & $\mathbf{9 . 0 3 8}$ \\
\hline $\mathbf{L C L _ { \mathbf { X } }}$ & $\mathbf{9 . 0 2 5}$ \\
\hline $\mathbf{C L}_{\mathbf{X}}$ & $\mathbf{9 . 0 3 1 2}$ \\
\hline $\mathbf{U C L}_{\mathbf{R}}$ & $\mathbf{0 . 0 6 1 6 4}$ \\
\hline $\mathbf{L C L}_{\mathbf{R}}$ & $\mathbf{0 . 0 1 8 3 6}$ \\
\hline $\mathbf{C L}_{\mathbf{R}}$ & $\mathbf{0 . 0 3 2 5 6}$ \\
\hline
\end{tabular}

The results shown in table 3 are taken from the Process Capability Graph figure 2 and X$R$ bar control charts figure 3 shows that the process is almost in center but $C_{p}$ is less than 1 which means process is not capable. The study shows a very rare case in which process is in center but not capable. The reason being its limited width with no room for error during the process.

\section{FINDING THE ROOT CAUSES FOR THE VARIATION}

To find out the root cause, cause and effect diagram was drawn which is shown in Figure 5. 


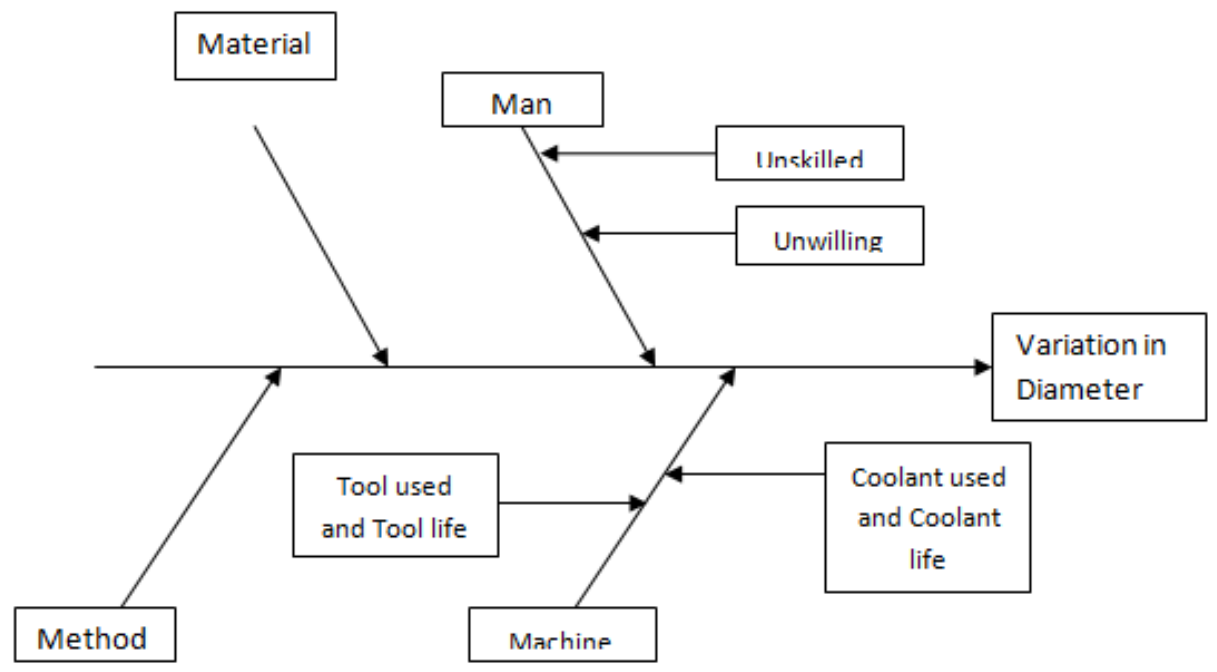

Fig 5: Root cause diagram

Possible causes of variation in diameter of the process are mostly due to machine causes and man causes. Sometimes Tool used and the coolant type and life cause errors in the machining process. Following are the observations that are made during the study:

1. The quality of the material should be checked before starting the machining process because it might be possible that it was not up to the standards

2. Tool used should be changed after machining of 100-110 pieces.

3. Coolant quality should be regularly checked

4. Coolant filters are to be cleaned at regular intervals especially in the case when coolant is not changed for a long time.

After analyzing these causes it is observed that coolant overused which in turn damaging the tool and producing variations in the diameter. The variations can be minimized by removing these causes.

\section{REFERENCES}

[1]. Quality management in the Bosch group.9 Machine and process capability Edition 1/7/2004

[2]. Parvesh Kumar Rajvanshi, Dr. R.M.Belokar. Improving the Process Capability of a Boring Operation by the Application of Statistical Techniques. International Journal of Scientific \& Engineering Research Volume 3, Issue 5, May-2012 ISSN 2229-5518 Engineering Research Volume 3, Issue 5, May-2012 1 ISSN 2229-5518

[3]. Aysun Sagbas. Improving the process capability of a turning operation by the application of statistical techniques. ISSN 1580-2949

[4]. Adeoye Akeem.O., Adedoyin,Salami.I., Alawaye Anthonia.I. Process Capability Analysis as a Means of Decision Making in Manufacturing Company. International Journal of Advanced Research in Computer Science \& Technology (IJARCST) Volume 1, Issue 1 Oct-Dec 2013 ISSN : 2347 - 8446 (Online) ISSN : 2347 - 9817 (Print) 
International Journal of Managing Value and Supply Chains (IJMVSC) Vol. 7, No. 3, September 2016

[5]. Sachin Prakash Wanare. Performance Analysis of Vertical Machining Center through Process Capability. Iinternational journal for innovation in engineering and technology Volume 1, Issue 1 Oct-Dec ISSN:2319-1058

[6]. Manoj Kumar Sain, Deepankar Pacheria, Sarita Choudhary. Performance Analysis of Vertical Machining Center through Process Capability SKIT research journal volume 5, issue 1:2015 ISSN 2278-2508

[7]. Douglas M. Montgomery .Introduction to Statistical Quality Control 6th edition 978-0- 47016992-6 Printed in the United States of America. 